\title{
O Direito Universal à Saúde em Risco: A Fragilidade Histórica do Financiamento e as Incertezas dos Governos Lula
}

\section{Health Universal Right at Risk: Financing Historical Weakness and Lula's Government Uncertainties}

\author{
Áquilas Mendes* \\ Rosa Maria Marques**
}

Resumo: Este artigo procura identificar os conflitos que estiveram presentes nas bases de financiamento do SUS, ao longo de duas décadas de sua existência, destacando a permanência dos constrangimentos e das incertezas que cercearam seu desenvolvimento durante os anos dos governos Lula. Ao final desses governos, os conflitos continuam abertos e estão longe de serem resolvidos, na medida em que o SUS não conseguiu, até o momento, ter fontes estáveis, definidas e seguras para seu financiamento e dispor de um gasto público em saúde, condizente com a média dos demais países que têm sistema universal. Argumenta-se que, para enfrentar essa situação, teria sido importante que os governos Lula, antes mesmo de aumentar recursos, tivessem elevado a saúde à condição de prioridade entre as políticas de governo, valorizando-a como um direito social universal.

Palavras-chave: Saúde universal. Financiamento do SUS. Governos Lula.

Abstract: This article searches to identify the conflicts which have been existed in SUS financing bases through its two decades of existence, stressing the staying of constraints and uncertainties which retrench its scheme, during the years of Lula's governments. In the end of these governments, the conflicts are kept opened and they are far from being solved, in the sense that SUS has not managed up, to the moment, acquire safe, clearly defined and stables sources to its financing and has not achieved an appropriated level of health public expenditure, comparable to other countries which have universal health systems. It argues that to face this situation, it had been important that Lula's governments, before increasing resources, should have raised health to a priority condition amongst government policies, appraising it as an universal social right.

* $\quad$ Professor doutor em Economia da Saúde da Faculdade de Saúde Pública da USP e do Departamento de Economia da PUCSP. E-mail: aquilasn@uol.com.br

** Professora titular do Departamento de Economia e do Programa de Estudos Pós-Graduados em Economia Política da PUCSP. Líder do Grupo de Pesquisa Políticas para o Desenvolvimento Humano. E-mail: rosamkmarques@gmail.com 
Keywords: Universal health. SUS financing. Lula's governments.

JEL Classification: I18.

\section{Introdução}

Em grande parte dos países europeus assiste-se, após 2008 e de forma objetiva, a dinâmica deflagrada pela crise do capital e seus impactos: redução dos direitos sociais. Tais reduções ocorrem por meio das medidas de restrição orçamentária decretadas pelos governos, como uma resposta técnica aos imperativos financeiros da crise econômica internacional.

No Brasil divulga-se um quadro, pelo menos aparente, totalmente diverso. Isso porque, quando o presidente Lula encerrava o seu segundo mandato, em 2010, a mídia brasileira destacava que seu governo havia acertado no conteúdo da políica econômica anticíclica (em 2009) para confrontar a crise e que seus altos índices de aprovação à sua gestão (85\% da população brasileira) demonstravam tal avaliação, além de refletirem os resultados positivos de suas várias realizações, em destaque a ampliação do campo das políticas sociais.

Não há dúvida que seu principal programa de transferência de renda, o Bolsa Família, foi responsável por retirar milhões de famílias brasileiras (cerca de um quarto da população brasileira) da situação de pobreza e de pobreza extrema e contribuir para a diminuição da desigualdade (a renda desse programa foi responsável por 16\% da queda global da desigualdade entre 1999-2009); ${ }^{1}$ e que foi sob sua orientação que o valor real do salário-mínimo teve importante recuperação.

Contudo, quando se verifica de forma mais pormenorizada o tratamento dado a algumas políticas de direitos sociais - previdência e saúde, ambas integrantes da seguridade social -, observa-se que, ao longo dos governos Lula, há um distanciamento da valorização desses direitos, especialmente na área da saúde pública, o que não tem sido objeto de ampla divulgação e análise. ${ }^{2}$

Os conflitos por recursos financeiros para assegurar uma política de direito universal da saúde foram significativos a partir de 2003, tornando-se ainda mais intensos que a já trajetória complicada dos anos anteriores, especialmente os dos governos Fernando Henrique Cardoso, durante a década de 1990. Para atestar essa afirmação, basta lembrar que, em 1995, foram gastos pelo governo federal em proporção ao PIB cerca de 1,75\% com ações e serviços de saúde.

Passados quinze anos, esse gasto em proporção ao PIB praticamente se mantém $(1,85 \%)$, ou seja, os governos Lula nada fizeram para modificá-lo. E, ainda,

Para um quadro mais geral de quanto o Programa Bolsa Família contribuiu para a redução da pobreza e da desigualdade, ver Soares et al. (2010).

Para uma análise das contra-reformas realizadas na previdência - área que não é tratada nesse artigo - durante os governos Lula, ver Marques et al. (2010). 
se acrescentarmos o gasto dos governos estaduais e municipais, observa-se que, enquanto o Sistema Único de Saúde (SUS), quase 4,0\% do PIB, em 2009 (CARVALHO, 2010), o gasto público em saúde nos países com sistemas universais de saúde, como por exemplo, Reino Unido, Alemanha, Espanha, França, Suécia, e Canadá, foi, em média, 6,7\%, no mínimo. ${ }^{3}$

Os constrangimentos para garantir volume de recursos condizentes para o desenvolvimento do caráter universalista da saúde têm sido presentes desde a criação do SUS. Os embates decorreram, em última instância, da força dominante do capital portador de juros que começava a controlar as relações econômicas e sociais, ${ }^{4}$ assegurando a supremacia do mercado no âmbito das políticas sociais, e em determinar políticas macroeconômicas restritivas, levando a que existissem, com muita frequência, significativos cortes de recursos de seus orçamentos, pressionando para a redução da participação do Estado em políticas sociais "de direitos".

Ao mesmo tempo que tudo isso acontecia, os governos Lula, desde o seu início em 2003, tentaram completar as reformas que seu antecessor havia deixado incompletas, principalmente no âmbito da previdência social - restringindo-a ainda mais - e na saúde, por meio do adiamento de soluções de um financiamento compatível à construção de uma política universal.

Na realidade, isso foi possível pela implementação de uma política econômica que tinha como principais objetivos cumprir metas de inflação e realizar superávits primários substantivos, com cortes nos gastos sociais, favorecendo largamente os interesses do capital financeiro nacional e internacional, possibilitando, de um lado, uma alta rentabilidade mediante a manutenção de elevadas taxas de juros e viabilizando um lucro bancário exorbitante, e de outro, uma expansão do agronegócio.

É certo que essa política econômica somente não foi seguida em 2009, devido aos efeitos significativos da crise econômica internacional, ${ }^{5}$ mas esteve presente ao longo de todos os outros anos, inclusive no último ano de 2010.

3 Dados da Organização Mundial da Saúde (2008). Para um detalhamento mais recente das características institucionais dos sistemas de saúde e do financiamento dos gastos desses países e de outros 27, membros da OCDE, ver Paris et al. (2010). Para uma discussão específica sobre os desafios do financiamento da saúde na União Europeia, ver Thomson et al. (2009).

4 Principalmente, a partir dos anos 1980, o capital portador de juros retornou com muito poder, após o período do pós-guerra em que ficou constrangido, determinando um novo comportamento ao Estado e garantindo o crescimento de sua forma parasitária e fictícia (CHESNAIS, 2005). O Brasil não ficou imune a esse quadro mais geral, principalmente a partir dos anos 1990, tornandose subordinado às forças que determinaram e movimentaram a nova fase do capitalismo em que foi presente, de forma definitiva, a dominância desse capital portador de juros, particularmente do capital fictício (MARQUES, 2009). Para uma abordagem teórica sobre os aspectos mais relevantes do funcionamento do capitalismo das últimas décadas, com ênfase no papel desempenhado pelo capital fictício e os desdobramentos da crise no momento atual, ver Marques e Nakatani (2011).

Nesse momento, as medidas tomadas pelo governo e pelo Banco Central do país foram direcionadas para: 1) estímulo ao crédito bancário; b) reestruturação bancária com a finalidade de se 
Apesar do avanço que significou a criação do SUS e seus efetivos resultados para a sociedade brasileira, ao longo de duas décadas de existência os governos Lula mantiveram a mesma tensão presente aos anos que se seguiram à Constituição de 1988: o embate entre a tentativa de construir a universalidade e o da contenção de gastos.

Este conflito continuou aberto ao longo dos governos Lula e está longe de ser resolvido. Seu resultado diz respeito a uma indefinição quanto ao lugar de um sistema púbico universal nos cuidados com a saúde. Desse modo, é possível entender o porquê de o SUS não ter, até o momento, conseguido definir fontes estáveis e seguras para seu financiamento e não dispor de um gasto público em saúde, condizente com a média dos demais países que dispõem de sistema similar. Para enfrentar essa situação, teria sido importante que o governo Lula, antes mesmo de aumentar recursos, tivesse elevado a saúde à condição de prioridade entre as políticas de governo, valorizando-a como um direito social universal. Porém, isso não parece ter sido a escolha do legado Lula.

É da compreensão de que a prioridade dada ao capital portador de juros no Brasil, ao longo dos governos FHC e em continuidade nos governos Lula, sustentou a permanência de uma política econômica neoliberal que trouxe inúmeras consequências às políticas sociais de direitos, diminuindo inclusive o seu conteúdo de política. ${ }^{6}$ Isso porque a adoção de políticas macroeconômicas, regidas por metas de inflação e dívida pública constrangida e/ou de superávits primários, levou a diminuição dos gastos públicos com direitos sociais, em destaque na saúde, aumentando os riscos da desuniversalização e assistencialização das políticas sociais. ${ }^{7}$ Vive-se, no momento do pós-anos Lula, um estado de distanciamento da efetivação da política de direitos universais da saúde, o que vem determinando as difíceis condições de financiamento do SUS e da Seguridade Social.

O presente artigo procura identificar os conflitos que estiveram presentes nas bases de financiamento do SUS, ao longo de duas décadas de sua existência, destacando a permanência dos conflitos e das incertezas que cerceiam seu desenvolvimento durante os anos dos governos Lula. Este artigo é fruto de vários anos de pesquisa e de acompanhamento do financiamento do SUS. Por isso, ele se vale de

proteger contra a insolvência de alguns bancos mais frágeis ou menores; c) incentivo à demanda através da renúncia fiscal e mudança no imposto de renda para pessoas físicas; e d) apoio aos desempregados, mediante ampliação do seguro desemprego. No seu conjunto, tais medidas levaram à queda da taxa de juros, ao aumento da despesa pública e à redução do superávit primário (MARQUES; MENDES, 2010).

6 Tal conteúdo deve ser associado à ponderação que Maar (2007, p.114) faz da contradição da política nesse contexto, evidenciando uma indagação: “[...] por que a política, por mais que hoje seja orientada aos excluídos, se torna simultaneamente também cada vez mais excludente?”. Para uma discussão acerca do conflito entre a política e sua forma instrumental, ver Maar, Woflgang Leo (2007).

$7 \quad$ Foram adotadas as expressões utilizadas por Behring (2008) - desuniversalizar e assistencializar -, ao se referir aos efeitos das políticas neoliberais, materializados por meio dos cortes nos gastos sociais, contribuindo para o equilibrio financeiro do setor público. 
partes de vários textos anteriores, na tentativa de fazer uma síntese dos principais elementos que colocam em risco o direito à saúde universal.

Além da introdução, o artigo está estruturado em mais três partes e considerações finais. A primeira parte aponta as condições gerais da atual fase do capitalismo de dominância do capital portador de juros, que não eram mais aquelas do período do pós-guerra, indicando como essa nova fase constrangeu a trajetória brasileira, principalmente quanto à ação de seu Estado, inibindo a garantia da universalização da saúde. São lembrados, nessa parte, os desdobramentos da crise estrutural do capitalismo no momento atual.

A segunda parte é dedicada a salientar os embates na trajetória de financiamento do SUS, durante seus 22 anos de existência. A terceira parte apresenta o agravamento das tensões do direito universal da saúde no período recente Governos Lula -, confirmando as incertezas do financiamento do SUS até o momento. Por fim, nas considerações finais são apresentadas algumas propostas para garantir e ampliar os direitos sociais, especialmente a saúde universal.

\section{Domínio do Capital Portador de Juros e os Embates à Saúde Universal $^{8}$}

A universalização de direitos sociais, consagrados na Constituição de 1988, teve como princípio fundador a adoção da cidadania como critério de acesso, modificando os pilares básicos do sistema anterior de proteção social. Nesse sentido, foram assegurados direitos básicos e universais de cidadania, estabelecidos à saúde, à assistência social e à previdência, integrantes do nosso particular sistema: a seguridade social. De uma situação em que o serviço público era voltado apenas aos trabalhadores contribuintes do mercado formal, passou-se à garantia do direito para todos.

Para o entendimento do que está em disputa quando se discute a saúde, merece ressaltar que esse padrão de proteção social, que assegurou o direito de universalização da saúde pública no Brasil, desenvolveu-se, em relação aos países desenvolvidos, de forma "tardia", não somente em relação ao tempo, mas, sobretudo, em referência ao momento histórico que se inseriu.

Essa interpretação se apoia na compreensão da natureza do processo experimentado pelo capitalismo nas últimas décadas, em que o capital portador de juros, mas mais especificamente em sua forma de capital fictício, assumiu centralidade nas relações sociais e econômicas do capitalismo contemporâneo. O capital fictício, ao se constituir na forma mais acabada do capital portador de juros, propicia à relação capitalista atingir a forma mais reificada e fetichizada. Marx (1987, p. 373) esclarece: “[...] temos nessa forma D-D', o dinheiro que gera mais dinheiro,

\footnotetext{
Esta parte se beneficia de Marques e Mendes (2009) e de Marques e Nakatani (2011).
} 
valor que se valoriza a si mesmo sem o processo intermediário que liga os dois extremos", quando se refere à forma geral do movimento do capital (D - M - D'). É fato que, a partir do início dos anos 1980, o ressurgimento do capital produtor de juros era duradouro e que ele determinava as relações econômicas e sociais do capitalismo contemporâneo. "O capital portador de juros", (com o seu desdobramento na forma de capital fictício) acrescenta Chesnais (2005, p.35), “[...] busca fazer dinheiro sem sair da esfera financeira, sob a forma de juros de empréstimos, de dividendos e outros pagamentos a título da posse de ações e de lucros nascidos da especulação bem sucedida". Nesse sentido, Chesnais (2005) enfatiza o caráter inédito e protagonista que a propriedade e o rentismo marcam na fase do capitalismo após o final dos anos 1970, assim como a permanência de seu papel exterior à produção no âmago da própria produção. A rigor, a consequência mais importante dessa centralidade do capital portador de juros (também chamado de capital financeiro) é que esse caráter de exterioridade que caracteriza esse tipo de capital vai ser remetida ao próprio âmbito da acumulação produtiva.

Quando se atribui ao momento contemporâneo do capitalismo a ideia principal de dominância da valorização financeira (do capital portador de juros, no seu desdobramento como capital fictício), não significa que essa valorização financeira seja mais importante que a valorização produtiva, do ponto de vista quantitativo, ainda que a riqueza financeira venha crescendo de forma exorbitante nas últimas três décadas. ${ }^{9}$ Trata-se de frisar que a predominância da valorização financeira é mais qualitativa do que quantitativa. O movimento do capital, neste período, priorizou diferentes estratégias para refazer a sua taxa de lucro utilizando-se de vários mecanismos como: a precarização do trabalho, a diminuição dos salários, a transferência de plantas para locais onde os salários sejam menos elevados, entre outras (MARQUES; NAKATANI, 2011). ${ }^{10}$

Assim, é possível deixar claro que o momento histórico da mudança do regime de acumulação capitalista em direção a um regime com dominância da valorização financeira inicia-se, principalmente, a partir dos anos 1980. Isso significa dizer que essa fase contemporânea do capitalismo ganha mais força após anos de crescimento mundial vigoroso produzido pelas políticas de caráter keynesiano, com controle de demanda efetiva e estado de bem-estar social. Assiste-se ao pro-

$9 \quad$ Entre 1980 e 2006, o PIB mundial cresceu 364\%, ou seja 4,6 vezes, enquanto que a riqueza financeira mundial cresceu, no mesmo período, 1.525\%, ou 16,2 vezes (McKinseys Global Institute (Ativos) e FMI (PIB) apud PAULANI, 2010)

10 Além disso, é importante ressaltar que a força do movimento do capital em promover tais mudanças, contou com derrotas significativas no mundo do trabalho. Marques e Nakatani (2011) chamam a atenção para a derrota das greves dos aeroviários nos Estados Unidos e dos mineiros, na Inglaterra, no início dosa anos 1980. Marques e Nakatani (2011, p. 3) acrescentam, ainda, os seguintes embates: "[...] mais tarde, essa correlação de forças se aprofundou com a queda do Muro de Berlim e com a dissolução da União Soviética. Para completar esse quadro, que colocou os trabalhadores pela primeira vez em verdadeira concorrência mundial, a China entrou na Organização Mundial do Comércio em 2001". 
cesso de reversão cíclica e o crescimento econômico desacelera-se. Dessa forma, ao contrário do que ocorreu no período em que a proteção social do Estado de Bem-estar Social europeu e norte-americano se desenvolveu, não era mais o capital industrial que comandava o processo capitalista.

O domínio do capital portador de juros teve grande impacto sobre o arranjo da proteção social conhecido como Estado de Bem-Estar Social e sobre a relação capital/trabalho. Mesa-Lago (2000) salienta que, desde o início da crise, os ataques e os questionamentos ao Estado de Bem-Estar Social tornaram-se mais intensos, não sendo poucos os países que introduziram dispositivos que aumentaram a participação do usuário no custeio das ações e serviços de saúde e limitaram a lista de medicamentos gratuitos, entre outros.

Nesse mesmo período, o capital produtivo, sufocado pela dominação financeira, foi levado a constranger os trabalhadores. A diminuição do custo da força de trabalho passou a ser fundamental, tendo em vista a força do capital portador de juros ao retirar o excedente criado na produção. De acordo com Husson (2003), o capital produtivo impôs diminuição dos níveis salariais e defendeu a eliminação dos encargos sociais e a redução substantiva dos impostos, elementos constitutivos do financiamento da proteção social de diversos países.

Já o mercado de trabalho apresentava alterações significativas com relação a sua realidade anterior. $\mathrm{O}$ desemprego, antes restrito a problemas decorrentes do sistema imperfeito de informações entre a demanda e a oferta (o chamado desemprego friccional), passou a registrar elevadas taxas no mundo desenvolvido.

A rigor, no momento em que os constituintes brasileiros redigiam a Constituição Cidadã de 1988, o país sentia intensamente os efeitos dos problemáticos conflitos decorrentes dessa nova situação mundial já há algum tempo.

Sabe-se que, a partir de 1982, quando o país recorreu formalmente ao Fundo Monetário Internacional (FMI) subordinando-se ao cumprimento das condicionalidades deste organismo, passando ainda pelas várias tentativas de controlar o processo inflacionário galopante, pelas privatizações das empresas estatais e pelo estímulo à entrada de capitais externos mediante a manutenção de elevada taxa de juros, o que entre outros motivos, tornou a dívida interna um problema, assistiu-se à modificação do Estado brasileiro. Esse Estado desenvolvimentista, que havia sido elemento-chave do processo de industrialização, investindo em infraestrutura e criando estatais produtoras de matérias-primas essenciais e que também tinha se preocupado em desenvolver o sistema público de proteção social, estava reduzido a poucas funções. A contenção do gasto público, primeira orientação do Consenso de Washington de 1990, dirigida tanto ao combate à inflação como à criação de um superávit primário fiscal, afastou o Estado de suas antigas funções, associadas ao período de desenvolvimentismo, entre 1930 a 1979.

É nesse cenário de novos constrangimentos para a economia brasileira e de um Estado manietado que a Constituição de 1988 introduziu o conceito de 
seguridade social e definiu a saúde pública como um direito de todos e um dever do Estado. Ao contrário do que ocorreu quando da universalização da saúde nos países desenvolvidos europeus, o Brasil não mais crescia de forma duradoura, seu Estado estava encolhido em relação ao seu passado. Nesse quadro, a trajetória de implementação do SUS, ao longo dos anos 1990 e 2000, realiza-se de forma contraditória, entre avanços e retrocessos, com redução nas bases das receitas que o fundamentam.

Por sua vez, se há algo que marca o momento atual é a manifestação problemática da crise estrutural do capitalismo, no seu modo de funcionamento sob a dominância do capital portador de juros. Ao ficar identificada a crise nos Estados Unidos em 2008, manifestou-se a real natureza do capital atualmente dominante. Percebe-se que o capital assegura altas taxas de rentabilidade e garantias, mas, como as bases que o fundamentam, referem-se a títulos públicos ou privados que, na sua grande maioria, não dispõem de relação com sua origem; tais taxas são direcionadas ao desmoronamento da relação de cobertura criada a partir dos anos 1980, configurando uma crise de superprodução. Para se ter uma ideia, a indústria automobilística nos EUA apresentava capacidade de produção de 18,3 milhões de unidades em 2008; já em 2009 conseguiu produzir somente 11 milhões. O quadro não era distinto na capacidade de produção no mundo, em que se dispunha de uma capacidade de 90 milhões de automóveis, viabilizando uma produção de apenas 66 milhões (GOLDESTEIN, $2011^{11}$ apud MARQUES; NAKATANI, 2011).

Contudo, essa crise não ficava restrita apenas ao problema da capacidade ociosa industrial. Criavam-se milhões de desempregados, ao mesmo tempo em que o capital excedente, na expressão do capital fictício, acumulava-se na esfera financeira por meio do crescimento do valor acionário, da dívida pública e dos derivativos. Trata-se do crescimento exponencial das dívidas dos bancos e de governos de alguns países na Europa - Grécia, Portugal, Irlanda e Espanha. ${ }^{12}$

Essa crise tem repercussões avassaladoras sobre a economia mundial, atingindo a todos os países. O Brasil não foi exceção. Depois de ter apresentado um PIB de 5,4\%, em 2007, registrou, em 2008, um crescimento inferior de 5,1\%, devido a acentuada desaceleração (-3,4\%) no último trimestre. Em 2009, o PIB ser retraiu significativamente, tendo seu resultado final negativo. Ocorre, nesse ano, uma diminuição da produção industrial de 5,5\% e do setor agropecuário de 5,2\%, sendo que as exportações diminuíram em 10,3\%.

Em que pese a recuperação da economia brasileira em 2010, em função das medidas realizadas pelo governo para enfrentar a crise, não se deixou de presenciar uma queda de arrecadação das receitas do governo federal, decorrentes

${ }_{11}$ GOLDSTEIN, Fred. Capitalism at a dead end. The Era of Job Destruction. A marxist view. In: XVI ENCONTRO NACIONAL DE POLÍTICA SOCIAL, 16., 2011, Vitória, ES. Anais... Vitória, ES, 2011.

12 Para um detalhamento do endividamento e do confronto das economias europeias, no período recente, à perspectiva de uma longa recessão, ver Chesnais (2011). 
desse cenário, assistindo-se também a alguns cortes considerados nos valores do orçamento de todas as áreas,,$^{13}$ sem exceção para as políticas sociais, em geral, e para a saúde em particular.

Mesmo com as medidas anticíclicas realizadas pelo governo Lula para enfrentar a crise econômica em 2009, não foi possível vislumbrar mudanças significativas na condução da política econômica, buscando diminuir a fragilidade da economia do país. Dois exemplos dessa situação são lembrados por Marques e Nakatani (2011). Em primeiro lugar, percebe-se que, ao final de 2008 e 2009, o quadro de extrema vulnerabilidade ao capital, tanto na forma de investimento estrangeiro direto (IDE), como na forma de capital especulativo e parasitário de curto prazo, não foi alterado. Para se ter uma ideia dessa situação, identifica-se o aumento da participação dos investimentos diretos e em carteira na composição do passivo externo brasileiro, crescendo as remessas relativas a lucros e dividendos para o exterior (conta renda e serviços do balanço de pagamentos). Entre 2006 e 2010 , a conta investimento direto passou de US $\$ 18,88$ bilhões para 48,88 bilhões, enquanto que o investimento em carteira (capital a curto prazo) saltou de US\$ 9,08 bilhões para US $\$ 67,8$, respectivamente. Em segundo lugar, outro dado que qualifica a fragilidade da economia brasileira frente a uma piora das condições da economia internacional diz respeito ao comportamento dos componentes da exportação no País. Nota-se que, entre 2006 a 2010, a participação dos produtos básicos no total das exportações cresceu significativamente, passando de 29,23\%, no primeiro ano, para $44,58 \%$, no último ano. Por sua vez, na composição dos produtos industrializados, os manufaturados diminuem sua participação de 54,44\% para 37,42\%, no mesmo período, tornando-se evidente a fragilidade da economia brasileira (MARQUES; NAKATANI, 2011).

Assim, é possível mencionar que a crise do financiamento do SUS, a partir desse ambiente de dominância do capital portador de juros, foi explicitada pela adoção de uma política macroeconômica restritiva, principalmente ao longo dos governos FHC e Lula. Tal política esteve voltada para o cumprimento de metas de inflação e de superávit primário, resultando em montantes insuficientes e indefinidos de recursos para o SUS. Além disso, manifestam-se tentativas de diminuição dos gastos na saúde e de reduzida participação dos recursos fiscais no financiamento da saúde, em contraposição à destacada participação da fonte de contribuições sociais - mais de dois terços do financiamento total. Não é de estranhar, portanto, que esse esquema do financiamento vem dificultando a efetivação dos princípios do SUS, a universalidade. E, com os desdobramentos da crise dessa fase

$13 \quad$ No dia 19 de março de 2009, o governo federal anunciou cortes de $\mathrm{R} \$ 21$ bilhões no orçamento daquele ano. A justificativa do governo foi a forte queda da arrecadação, causada pela diminuição da atividade econômica, em razão da crise. Ao mesmo tempo, mantém intocado o pagamento da dívida ao contrário de auditá-la, conforme prevê a Constituição Federal de 1988. 
do capitalismo contemporâneo, o quadro que se vislumbra ao financiamento da saúde universal não parece que irá se comportar de maneira distinta.

\section{Um caminho de embates no financiamento do SUS}

Qualquer que seja o diagnóstico, no entanto, é crescente a percepção de que a saúde universal enfrenta problemas no seu esquema de financiamento, inviabilizando a realização de uma política mais efetiva. Em outras palavras, o quadro deteriorado do financiamento do SUS, acrescido do agravamento das questões sociais no país, evidencia, ainda mais, a crise do sistema público. Nessa situação, é preciso analisar o fio condutor que dá origem ao problemático financiamento da saúde ao longo dos anos 1990 e 2000.

Cabe salientar que, para os novos direitos introduzidos na universalização da saúde e na área previdenciária, a Constituição de 1988 preocupou-se em ampliar os recursos destinados ao financiamento da Seguridade Social - saúde, previdência e assistência social. Assim, além das fontes tradicionalmente utilizadas pelo sistema previdenciário, foi criada a Contribuição sobre o Lucro Líquido e incorporada à receita do Finsocial (atualmente Cofins) para seu único uso.

Para garantir o financiamento das despesas de proteção social, ampliadas pela adoção da Seguridade Social, os constituintes definiram que o financiamento da Seguridade Social seria realizado "mediante recursos provenientes dos orçamentos da União, dos Estados, do Distrito Federal e dos Municípios", e das contribuições sociais dos empregadores (incidentes sobre a folha de salários, o faturamento - Cofins - e o lucro - Contribuição sobre o Lucro Líquido (CSLL), dos trabalhadores e 50\% da receita de concursos e prognósticos (loteria). Ficou estabelecido, ainda na Constituição, que esses recursos da Seguridade Social não integrariam o orçamento da União e sim da Seguridade Social (artigo 195). A incorporação das novas fontes Cofins e CSLL também visava tornar o financiamento menos dependente das variações cíclicas da economia.

Por meio de lei complementar, dispôs-se que 30\% dos recursos do OSS deveriam ser destinados ao SUS. A esses recursos, de origem federal, deveriam ser acrescidas, segundo a Constituição, receitas provenientes dos Tesouros Estaduais e Municipais, que viabilizassem a implementação desse sistema. A Constituição de 1988 não definia, entretanto, como seria a participação dos entes federados no financiamento da Seguridade Social.

Em 1997, foi criada a Contribuição Provisória sobre a Movimentação Financeira (CPMF), cujos recursos se somaram àqueles definidos na Constituição. Somente em 13 de setembro de 2000 foi aprovada a Emenda Constitucional $n^{\circ} 29$, estipulando a forma da inserção da União, dos Estados e dos Municípios no financiamento do Sistema Único de Saúde. 
Os constituintes também tiveram o cuidado de definir que as contribuições sociais seriam de uso exclusivo da Seguridade Social. Infelizmente nenhum governo que se seguiu à promulgação da Constituição de 1988 cumpriu esse dispositivo.

\subsection{A História dos Conflitos ${ }^{14}$}

Para detalhar a trajetória do financiamento do SUS a partir da Constituição de 1988, considera-se importante, antes de tudo, identificar a existência de um duplo movimento em seu caminho, resultado de ação permanente e contraditória de dois princípios que se imbricam, embora cada um deles aponte para objetivos específicos.

Por um lado, destaca-se o "princípio da construção da universalidade", que se expressa pelo direito de cidadania às ações e aos serviços de saúde, viabilizando o acesso de todos, por meio da defesa permanente de recursos financeiros seguros. Por outro lado, identifica-se o princípio da "contenção de gasto", uma reação defensiva que se articula em torno da defesa da racionalidade econômica, na qual a diminuição das despesas públicas constitui-se instrumento-chave para combater o déficit público, propiciado por uma política fiscal contracionista, e a manutenção de alto superávit primário em todas as esferas de atuação estatal. É da compreensão que esse "princípio" está diretamente associado à política econômica desenvolvida pelo governo federal durante as décadas de 1990 e 2000. Entre os vários argumentos na defesa desse princípio, destaca-se aquele que atribui aos direitos introduzidos pela Constituição a forte causa dos desequilíbrios nas contas do governo, provocando o déficit público. Desse modo, decorre a ausência de prioridade ao SUS, com redução de seu gasto. Em consequência, indaga-se sobre qual deveria ser a extensão da cobertura dos serviços realizados pelo SUS.

Esse duplo movimento na trajetória do financiamento do SUS após a Constituição de 1988 não deve ser entendido como se fosse uma sequência no tempo ou um movimento pendular. Trata-se de um movimento dialético, pois os dois princípios convivem de forma permanente e contraditória, ao longo do processo de implementação do SUS.

A defesa do princípio da construção da universalidade das ações e dos serviços de saúde, que acaba corrigindo a expansão da política econômica ortodoxa, manifesta-se, principalmente, no embate contra os ditames dessa política econômica, por meio da defesa da garantia de recursos financeiros.

A situação financeira da saúde universal, ao longo de todos os anos posteriores à Constituição, tem sido orientada por dois determinantes: a preocupação dada à Previdência no interior do orçamento da seguridade social e a política fiscal contracionista implementada pelo governo federal no campo social, decorrente de sua meta de reduzir despesas.

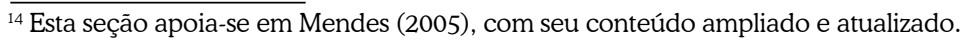


Em relação ao Orçamento da Seguridade Social, observa-se um conflito constante pela disputa de recursos ao longo de todos esses anos. O primeiro conflito foi verificado em 1989 e 1990, quando recursos do então Finsocial não foram totalmente destinados ao financiamento da Seguridade Social. Tais recursos contribuíram para o financiamento dos encargos previdenciários da União - despesa que não faz parte do orçamento da Seguridade Social.

No tocante à participação da Saúde no OSS, ainda que a Constituição de 1988 tenha determinado, em suas Disposições Transitórias, que pelo menos 30\% do total de recursos da Seguridade Social, com exceção da receita do PIS/PASEP, que é vinculada, deveriam ser destinados à área da saúde, com a aprovação da Lei Orgânica da Saúde, em fins de 1990, foi possível, ao então Ministério da Previdência Social, reduzir o volume desse repasse. A transferência para o Ministério da Saúde, que representava 33,1\% da receita de contribuições, em 1991, passou para apenas 20,9\%, em 1992.

O segundo momento de embate relevante aconteceu em 1993. Nesse ano, a Lei de Diretrizes Orçamentárias (LDO) estipulava que 15,5\% do total arrecadado a título de contribuições deveriam ser repassados para a área da saúde. No entanto, apesar do disposto na LDO, não foi efetuado nenhum repasse para a saúde em maio de 1993. A justificativa para tanto foi que a Previdência Social estava apresentando problemas financeiros que, caso as transferências prosseguissem, acabaria por encerrar o ano com déficit. Com a deteriorada situação financeira estabelecida na saúde, socorreu-se aos empréstimos dos recursos do Fundo de Amparo do Trabalhador (FAT).

Nesse período, entre 1989 e 1993, percebe-se certa especialização das fontes da Seguridade Social: os orçamentos destinaram a maior parte dos recursos do Cofins para a Saúde, da Contribuição sobre o Lucro para a Assistência e das contribuições de empregados e empregadores para a Previdência Social. Essa forma de utilizar as fontes de financiamento da Seguridade Social teve consequências problemáticas, especialmente para a saúde.

Uma terceira e significativa tensão no financiamento do SUS e da Seguridade Social ocorreu em 1994, com a criação do Fundo Social de Emergência (FSE) que, posteriormente, denomina-se Fundo de Estabilização Fiscal e, a partir de 2000, intitula-se Desvinculação das Receitas da União (DRU). A rigor, ficou definido, entre outros aspectos, que $20 \%$ da arrecadação das contribuições sociais seriam desvinculadas de sua finalidade e estariam disponíveis para uso do governo federal, longe de seu objeto de vinculação: cooperação para implementação das políticas de direitos sociais.

Nesse quadro de deterioração da situação financeira da seguridade social, especialmente, da área da saúde, o Conselho Nacional de Saúde e a Comissão de Seguridade Social da Câmara buscaram soluções transitórias. Defendeu-se a cria- 
ção, em 1994, do Imposto Provisório sobre a Movimentação Financeira (IPMF), que somente veio a vigorar a partir de 1997, sob a denominação de Contribuição Provisória sobre a Movimentação Financeira (CPMF). Nesse ano, a participação da CPMF, em bilhões de reais correntes, foi de $\mathrm{R} \$ 6,7$ bilhões, correspondendo a $27,8 \%$ do total das fontes do financiamento da saúde. Ao longo dos anos de sua existência, até 2007, sua participação em relação ao total das fontes de financiamento corresponde a cerca de $30 \%$. Contudo, o seu novo volume de recursos não significou o incremento esperado, uma vez que a Cofins e a CSLL foram reduzidas pelo governo federal, passando a ser transferidas crescentemente para a área previdenciária.

A crise provocada pelo não recebimento do repasse das contribuições sobre folha de salários, pela diminuição da presença de outras fontes da Seguridade e ainda pela desvinculação da CPMF, Cofins e CSLL em virtude da criação do FSE, teve repercussões no desempenho do gasto federal com saúde, a partir da segunda metade da década de 1990.

O gasto líquido com ações e serviços de saúde, excluindo os valores da dívida e de inativos e pensionistas, realizado pelo Ministério da Saúde, em proporção ao Produto Interno Bruto (PIB), no período entre 1995 e 2010, manteve-se praticamente estabilizado (1,7\%), indicando quase nenhum esforço do Ministério da Saúde. Além disso, esse reduzido esforço do gasto em "ações e serviços de saúde" em proporção ao PIB, realizado pelo MS, pode ser verificado também pelo comprometimento mais significativo do governo federal com o pagamento de Juros e Encargos da Dívida também em proporção ao PIB.

Observa-se uma evolução de 7,5\%, em 1995, para 8,5\%, em 2002 (período dos governos FHC); passando de 9,3\%, em 2003, para 5,1\%, em 2010 (período dos governos Lula). Nesse último ano, as despesas com juros e encargos da dívida foram de R $\$ 195$ bilhões, valor correspondente a 3,0 vezes o gasto do MS. Tem-se, então, que a política econômica ortodoxa em vigor, no período, tende a sacrificar os gastos sociais, como os voltados para a saúde universal, sem diminuir o ônus financeiro da dívida.

Vale ressaltar que, principalmente a partir de 1995, tornou-se mais clara a adoção de um conjunto de iniciativas voltadas ao ajustamento das finanças públicas. Na maior parte das vezes, as medidas implementadas direcionaram-se para a intrínseca relação que a lógica financeira (capital portador de juros) passa a ter dentro do próprio aparelho do Estado. Como mencionado na parte 1 deste artigo, a financeirização torna-se parte do Estado e este um instrumento para sua difusão e valorização do capital portador de juros, reduzindo drasticamente os gastos na área da saúde.

Por sua vez, embora o país atravesse um período de retração econômica, essa situação não tem provocado impacto negativo nas contas da Seguridade So- 
cial ao longo dos anos 2000. Logo após o penoso quadro financeiro da década de 1990, caso fosse respeitado pelo governo federal o conceito de Seguridade Social definido na Constituição de 1988 e não fosse utilizado o mecanismo de desvinculação dos $20 \%$ do antigo Fundo de Estabilização Fiscal e atual DRU, o orçamento da Seguridade contaria com superávits significativos, sendo $R \$ 27,3$ bilhões, em 2000 , e $\mathrm{R} \$ 66,3$ bilhões, em 2008 , todos em valores correntes.

Já, em 2009, o saldo superavitário foi de apenas $\mathrm{R} \$ 32,9$ bilhões,$^{15} \mathrm{em}$ razão da crise econômica, sendo que em 2010 voltou a crescer, atingindo $R \$ 58,1$ bilhões, sendo retirado pela DRU R $\$ 45,9$ bilhões. Os recursos excedentes, referentes aos saldos superavitários, segundo a Associação Nacional dos Fiscais da Previdência, foram alocados no pagamento de gastos fiscais ou contabilizados diretamente no cálculo do superávit primário (ANFIP, 2011).

Esse resultado positivo não alterou a posição do governo federal, que durante todos esses anos manteve acessa a ideia de um propalado déficit da Previdência, desconsiderando assim a sua vinculação ao orçamento da Seguridade Social. Interessante observar que essa falsa concepção contribuiu para a aprovação de reformas na Previdência seja no governo FHC seja no governo Lula (MARQUES; MENDES, 2009).

O quadro de incertezas e indefinições aos recursos financeiros para a saúde universal levou à busca de uma solução mais definitiva, qual seja: a vinculação dos recursos orçamentários das três esferas de poder. A história de construção de uma medida de consenso no âmbito da vinculação de recursos levou sete anos tramitando pelo Congresso até a aprovação da Emenda Constitucional n ${ }^{\circ} 29$ (EC 29), em agosto de 2000. Essa Emenda estabeleceu que Estados e municípios devem alocar, no primeiro ano, pelo menos, $7 \%$ dessas receitas, sendo que esse percentual deve crescer anualmente até atingir, para os Estados, 12\%, no mínimo, em 2004 e, para os municípios, $15 \%$ no mínimo.

No tocante à União, a EC 29 determina que, para o primeiro ano, deveria ser aplicado o aporte de pelo menos $5 \%$ em relação ao orçamento empenhado do período anterior; para os seguintes, o valor apurado no ano anterior é corrigido pela variação do PIB nominal. A EC 29 para a União não explicita a origem dos recursos e em relação à Seguridade Social foi omissa, como se não houvesse disputa por seus recursos.

As disputas por recursos foram presentes antes e após o estabelecimento da EC 29. A luta do SUS por recursos já vem de longo período, podendo seu primeiro conflito ser situado em 1993. No entanto, o importante é assinalar aquelas situações em que os constrangimentos econômicos, especialmente os derivados da exacerbação da lógica da política econômica dos governos após o Plano Real,

15 Segundo dados da Anfip (2011), 2009 foi o único ano em que a DRU superou o saldo positivo da seguridade social, correspondendo a $\mathrm{R} \$ 38,8$ bilhões. 
refletiram-se em ações que resultariam em menor disponibilidade de recursos para a saúde pública. Reconhecer o sentido das reformas econômicas e sociais implantadas nesse período, particularmente nos governos Lula, torna-se fundamental para evidenciar as fragilidades do esquema de financiamento da saúde universal.

\section{A Permanência dos Conflitos e das Incertezas do Financiamento do SUS nos Governos Lula}

A política macroeconômica dos governos Fernando Henrique Cardoso, e mais recentemente a vigente durante os governos Lula, determinaram as frágeis condições do financiamento do SUS. Sabe-se que o cumprimento das metas de inflação, com a permanência de altas taxas de juros, e de ajustes das contas externas, exigiu sempre superávits primários altos, resultando em tentativas de diminuição dos gastos públicos sociais e em contingenciamentos na Saúde.

No que diz respeito à saúde, merece destacar as situações nas quais os constrangimentos econômicos dados pela política macroeconômica dos governos Lula, especialmente os derivados do esforço de realização do superávit primário, refletiram-se em ações que resultariam em menor disponibilidade de recursos para essa área. As situações a seguir descritas e analisadas referem-se, no entanto, praticamente ao âmbito federal, muito embora eventos semelhantes tenham ocorrido nas demais esferas de governo. Ainda, cabe comentar, mais adiante, a ausência de tentativas desse governo de garantir a regulamentação da Emenda Constitucional 29 (EC 29), por meio da desconsideração e não aprovação do projeto original, que tinha o compromisso de inserir mais recursos, baseando a aplicação da União em 10\%, no mínimo, da Receita Corrente Bruta (RCB) - PLP 01/2003 -, largamente defendido pelas entidades vinculadas à saúde universal. Por último, cabe mencionar os problemas que se apresentam na proposta de reforma tributária do Governo Lula, rompendo com as fontes exclusivas do financiamento da Seguridade Social.

Em todos os anos do primeiro governo Lula, a equipe econômica tentou introduzir itens de despesa que não são considerados gastos em saúde no orçamento do MS. Entre esses itens figuraram, entre outros, as despesas com transferência direta de renda - Bolsa Alimentação. Embora essas tentativas estivessem apoiadas por toda a área econômica do governo, não se consolidaram, pois as entidades da área da saúde universal, tais como a Abrasco, o Cebes, a Abres, a Rede Unida, a Ampasa, o Conselho Nacional de Saúde e a Frente Parlamentar da Saúde rapidamente se mobilizaram e fizeram o governo recuar.

A mesma situação foi verificada por alguns Estados. Para cumprirem o disposto na EC 29, incluíram indevidamente como despesas em ações e serviços de saúde os gastos com inativos da área da saúde, empresas de saneamento, habitação urbana, recursos hídricos, merenda escolar, alimentação de presos e hospitais 
de "clientela fechada" (como hospitais de servidores estaduais). Esses registros indevidos foram presentes, apesar de anteriormente terem sido estabelecidos parâmetros que definiam quais ações e serviços poderiam ser considerados como gastos SUS. ${ }^{16}$ Em alguns municípios o mesmo ocorreu. Além disso, o percentual mínimo de aplicação de 15\%, estabelecido na EC 29 a ser aplicado, acabou sendo o percentual utilizado, mesmo que as necessidades exigissem aplicações maiores.

Outro aspecto que também chama a atenção, nos primeiros anos dos governos Lula, diz respeito às tentativas de redução do orçamento do MS. A Lei de Diretrizes Orçamentárias (LDO) para o orçamento de 2004 previa que os encargos previdenciários da União (EPU), o serviço da dívida e os recursos alocados no Fundo de Combate e Erradicação da Pobreza fossem contabilizados como gastos SUS do Ministério da Saúde. No entanto, resistência do Conselho Nacional de Saúde e da Frente Parlamentar da Saúde determinou que o Poder Executivo enviasse mensagem ao Congresso Nacional estabelecendo que, para efeito das ações em saúde, seriam deduzidos o EPU e o serviço da dívida.

Em relação ao Fundo da Pobreza a mensagem era omissa, resultando numa diminuição de $\mathrm{R} \$ 3,5$ bilhões no orçamento SUS do MS. Apesar de diversos e intensos debates que teriam ocorrido entre entidades vinculadas ao SUS e o Ministério do Planejamento, nada foi modificado sobre essa questão. Somente após o parecer do Ministério Público Federal, contrariando a decisão presidencial, sob pena de o orçamento aprovado vir a ser considerado inconstitucional, o governo recuou.

No mesmo sentido, o projeto da LDO para o orçamento de 2006 previa que as despesas com assistência médica hospitalar dos militares e seus dependentes (sistema fechado) fossem consideradas no cálculo de ações e serviços de saúde. Se essa despesa fosse considerada, os recursos destinados para o MS seriam reduzidos em R $\$ 500$ milhões, aproximadamente. Depois da declaração pública do MS repudiando essa interpretação, acrescido da mobilização das entidades da saúde, o governo federal foi obrigado a reformular sua proposta.

Há, ainda, que lembrar os embates contra a vinculação de recursos da EC 29 que permaneceram presentes pela equipe econômica do governo Lula, desde os seus primeiros anos de gestão. Ao final de 2003, o governo federal encaminhou documento referente ao novo acordo com o Fundo Monetário Internacional - dirigido ao seu diretor executivo -, comunicando sua intenção em preparar um estudo sobre as implicações das vinculações constitucionais das despesas sociais sobre as receitas dos orçamentos da União, dos Estados ou dos municípios.

Justificava-se que a flexibilização da alocação dos recursos públicos poderia assegurar uma trajetória de crescimento ao país (BRASIL, 2004, p. 3). No âmbito

$16 \quad$ Esses parâmetros foram acordados entre o Ministério da Saúde, os Estados e seus tribunais de contas, por meio da Resolução n ${ }^{\circ} 322$, do Conselho Nacional de Saúde - homologada pelo Ministro da Saúde em 8 de maio de 2003. 
do SUS, a intenção do governo era tirar do MS a obrigação de gastar, em relação ao ano anterior, valor igual acrescido da variação nominal do PIB, tal como define a EC 29.

Mesmo com essa visão oficial contrária à EC 29, a avaliação é que a sua aprovação permitiu que o gasto SUS aumentasse de $2,89 \%$ do PIB, em 2000, para quase $4,0 \%$ do PIB, em 2009, ainda insuficiente para ser universal e garantir o atendimento integral. No entanto, como mencionado na Introdução deste artigo, o gasto público brasileiro é baixo em relação ao dos demais países que têm um sistema público universal.

Para que o Brasil atingisse o nível desses países, precisaria quase dobrar a participação do SUS em relação ao PIB. Além disso, segundo a Organização Mundial da Saúde (2008), a participação do gasto público no total da despesa com saúde também é baixo no país: cerca de 44,1\%. Nos demais países, como Alemanha, Reino Unido, Suécia e Espanha, o percentual é, em média, 80\%. No caso brasileiro, ainda, é significativo o incentivo concedido pelo governo federal à saúde privada, na forma de redução de imposto de renda a pagar da pessoa física ou jurídica, o que é aplicada sobre despesas com Plano de Saúde e/ou médicas e similares. E, ainda, cabe acrescentar as renúncias fiscais que experimentam as entidades sem fins lucrativos e a indústria farmacêutica, por meio de seus medicamentos (SERVO et al., 2011). Há dados que indicam que o total desses benefícios tributários à saúde privada vem crescendo de forma considerada. Registre-se: $R \$ 7,8$ bilhões, em 2007; R \$ 8,7 bilhões, em 2008; e, R \$12,1 bilhões, em 2009 (BRASIL, 2012).

\subsection{As Tensões na Regulamentação da EC 29}

A regulamentação da EC 29 ficou pendente quase 8 (oito) anos no Congresso, entre 2003 e 2011 , provocando perda de recursos para o SUS e enfraquecimento do consenso obtido, quando de sua aprovação. De acordo com informações do Sistema de Informações sobre Orçamento Público em Saúde (Siops), a diferença entre o valor mínimo previsto e o valor efetivamente aplicado pela União, entre 2000 e 2009 , atinge $R \$ 3$ bilhões. Se a isso se soma ao montante cancelado de Restos a Pagar, de $\mathrm{R} \$ 2,6$ bilhões, e se os gastos registrados indevidamente como SUS forem subtraídos, tais como Bolsa Família, ações e serviços de saúde para servidores e Farmácia Popular, a diferença alcança R $\$ 6$ bilhões (PIOLA, 2010).

A regulamentação da EC 29 não se revelou uma prioridade nos governos Lula. Isso porque a política macroeconômica implementada pelos seus dois governos, ao dar prosseguimento ao que era feito por FHC, tinha como objetivo central o cumprimento de metas de inflação e a obtenção de elevados superávits primários, resultando em constante pressão para que o gasto público social fosse diminuído. A inclusão da EC 29 na pauta do Congresso, em abril de 2006, deveuse tão somente à ação da Frente Parlamentar da Saúde. A matéria continuou a 
enfrentar dificuldades para sua aprovação até o final de 2010 - último ano do segundo governo Lula.

A rigor, o interesse do governo em relação à EC 29 somente se manifestou quando da discussão sobre a continuidade da CPMF, ao final de 2007. Nesta ocasião, ele apresentou uma contraproposta ao PLP 01/2003 ${ }^{17} \mathrm{em}$ que, no lugar de garantir para a Saúde um percentual mínimo das receitas de seu âmbito, propunha um acréscimo escalonado da participação da CPMF em seu financiamento. Pensava o governo que essa imbricação entre a continuidade da CPMF e o financiamento da Saúde iria assegurar a prorrogação dessa contribuição. Mas já que o Senado não aprovou a CPMF, a proposta do governo não teve prosseguimento. ${ }^{18}$

Em abril de 2008, projeto similar ao PLP n ${ }^{\circ}$ 01/2003 da Câmara, no Senado — PLS n ${ }^{\circ} 121 / 2007$-, foi aprovado com modificações importantes. A fórmula de cálculo para aplicação do governo federal, de no mínimo de $10 \%$ da Receita Corrente Bruta (RCB), foi alterada por meio da criação de um escalonamento ao longo de quatro anos, sendo que seriam aplicados $8,5 \%$ dessa receita, no primeiro ano, passando para $9 \%$, no ano seguinte, e $9,5 \%$, e $10 \%$ nos seguintes, respectivamente. Mas sua aplicação resultaria no aumento do gasto SUS de menos de $1 \%$ do PIB.

O projeto de regulamentação da EC 29 (PLS 121/2007) foi para aprovação na Câmara sob uma nova denominação: PLP 306/2008. Ao receber esse Projeto, a Câmara encaminhou um substitutivo global a ele, no qual novamente introduzia a correção dos recursos da União pela variação nominal do PIB. Além disso, resgatou a ideia de uma CPMF, porém nesse momento como CSS - Contribuição Social para a Saúde -, isto é, com a mesma base tributária que a CPMF, só que com alíquota de $0,10 \%$ e não mais $0,38 \%$. Se a CSS fosse aprovada, sua arrecadação estimada seria de $\mathrm{R} \$ 12,5$ bilhões. Mas, desse montante, era necessário subtrair $20 \%$ da DRU e os R $\$ 7$ bilhões devidos ao Fundo de Manutenção e Desenvolvimento da Educação Básica (previsto no projeto). Desse modo, o orçamento do Ministério da Saúde de 2010 passaria de $R \$ 62,5$ bilhões para $R \$ 66,5$ bilhões, com valores

17 Dentre os principais itens do projeto de regulamentação da EC 29 (PLP 01/2003), de autoria do então deputado Roberto Gouveia (PT/SP), destacam-se dois: 1 - a modificação da base de cálculo para a vinculação dos recursos da União, passando do valor apurado no ano anterior corrigido pela variação do PIB nominal para 10\%, no mínimo, da sua Receita Corrente Bruta - sem inclusão das receitas de capital e das decorrentes de operação de crédito; 2 - a definição das despesas que devem ser consideradas como ações e serviços de saúde e daquelas que não se enquadram nesse conceito. Para se ter uma ideia do significado dos $10 \%$ da Receita Corrente Bruta proposto, cabe informar que os gastos federais com ações e serviços públicos de saúde (SUS) diminuíram em relação às receitas correntes brutas da União, após 1995. Representaram, em média, 8,37\% da RCB no período 1995 a 2001, reduzindo-se, no período de 2002 a 2009, para 7,1\% da RCB, na média (PIOLA, 2010).

18 O PLP 01/2003 foi aprovado na Câmara e enviado ao Senado, onde foi aprovado. Porém como essa aprovação contava com os recursos da CPMF, ele deixou de ser viável. A alocação de $10 \%$ da Receita Corrente Bruta da União para a Saúde, prevista no texto inicial do projeto foi retirada no último momento, quando de sua aprovação na Câmara, e mantida a forma de cálculo anterior, além de contemplar recursos da CPMF. 
bastante inferiores ao projeto original do Senado (PLS 121/2007) (CARVALHO, 2010).

O projeto da Câmara PLP 306/2008 foi votado no primeiro semestre de 2008, ficando apenas na dependência da votação de um destaque que retirava do texto a CSS, sob a justificativa da oposição ao governo Lula que se tratava do retorno da CPMF. Este destaque permaneceu e a CSS foi derrotada.

Finalmente, com a ida desse projeto da Câmara ao Senado, tem-se a aprovação da regulamentação da EC 29, nessa última casa legislativa. Tal aprovação somente ocorreu em dezembro de 2011, já no final do primeiro ano do governo que sucedeu ao do presidente Lula, agora sob o comando da presidente Dilma Roussef. É possível dizer que essa regulamentação constitui uma grande derrota para o financiamento das ações e serviços do Sistema Único de Saúde (SUS). Nenhum novo recurso foi de fato destinado para garantir a universalidade da saúde. O projeto de regulamentação que se encontrava no Senado - PLS/127/2007 e não foi aprovado na versão original (aplicação da União em 10\%, no mínino, da Receita Corrente Bruta (RCB)) poderia ter acrescentado para o orçamento do Ministério da Saúde de 2011 o correspondente a R \$32,5 bilhões (CARVALHO, 2010). Basta lembrar que, em 2009, enquanto o SUS gastou 4,0\% do PIB (MS, governos estaduais e municipais), o gasto público em saúde nos países mencionados anteriormente foi, em média, $6,7 \%$, o que seria necessário obter $2,7 \%$ a mais, correspondendo a cerca de $\mathrm{R} \$ 92$ bilhões a mais em 2011.

Um dia depois de definido que o SUS não contaria com maiores recursos, o governo conseguiu aprovar no Senado, no mesmo mês de dezembro de 2011, o projeto que propunha a continuidade da DRU até 2015, dando continuidade a que $20 \%$ das receitas da seguridade social fossem dirigidas a outras finalidades, tais como o pagamento dos juros da dívida aos rentistas do capital financeiro e a manutenção do superávit primário.

O governo Dilma considerou a votação da prorrogação da DRU como a mais importante do ano, na medida em que, segundo seu argumento, seus recursos contribuirão para defender a economia brasileira da crise mundial. Nessa argumentação, o governo esqueceu-se do papel exercido pelas políticas sociais como sustentador da demanda efetiva, no qual a garantia das ações e serviços do SUS tem grande efeito multiplicador.

Por fim, e não menos importante, merece menção os riscos da proposta de Reforma Tributária do Governo Lula para a Seguridade Social e o SUS.

\subsection{Os Riscos da Proposta de Reforma Tributária de 2008 para a Seguridade Social e o SUS}

A proposta de reforma tributária do governo Lula, apresentada ao final de 2008, constituiu a pior ameaça aos direitos sociais introduzidos pela Constituição 
de 1988, especialmente sobre o sistema da Seguridade Social, mas também para as áreas de educação e trabalho. A proposta tinha como propósito simplificar o sistema tributário e desonerar os investimentos produtivos e a folha de salários. No tocante à União, essa reforma propunha a agregação dos impostos e extinção das contribuições sociais e econômicas que possuem semelhanças em sua base de incidência.

Quanto às contribuições sociais, seriam extintos o PIS, a Cofins e a Contribuição para o Salário Educação, dando lugar ao Imposto sobre valor Adicionado (IVA-Federal). Já a CSLL e o Imposto de Renda seriam unificados, gerando um imposto de renda mais amplo. ${ }^{19} \mathrm{O}$ projeto previa, ainda, a desoneração da contribuição patronal sobre a folha de pagamento, por meio de legislação específica, após as devidas alterações constitucionais.

Nessa perspectiva, a reforma tributária prejudicaria diretamente o financiamento da Seguridade Social, do Fundo de Amparo ao Trabalhador (FAT) e da educação básica (Salário-Educação). Os três tributos mais relevantes para a Seguridade Social seriam modificados. Em sua substituição, caberia à Seguridade Social $39,7 \%{ }^{20}$ do produto da arrecadação dos impostos sobre renda (IR), dos produtos industrializados (IPI) e das operações com bens e prestações de serviços (IVA-F), o que seria insuficiente para a realização de suas ações e serviços, bem como para o pagamento de benefícios. ${ }^{21}$

Assim, a Seguridade Social não contaria com recursos a ela exclusivos e o financiamento de suas áreas, principalmente do SUS, dependeria de uma partilha da arrecadação do IVA-F e das contribuições previdenciárias sobre folha de salário, de empregados e empregadores (que teriam alíquotas reduzidas). Sabe-se que a história recente de disputa por recursos entre as áreas econômica e social indica quão difícil seriam as negociações dessa partilha.

\section{Considerações Finais e Propostas para Assegurar o Direito Universal à Saúde}

Diante da predominância de políticas macroeconômicas neoliberais adotadas pelos governos FHC e mantidas pelos governos Lula, em consonância com a dominação do capital portador de juros no capitalismo contemporâneo, a trajetória do financiamento da Seguridade Social em geral e do SUS, em particular, tem permanecido completamente tensionada. Não foi à toa que o tema do finan-

\footnotetext{
19 Aqui foram mencionados apenas os aspectos que alterariam os impostos e as contribuições em vigor. Para maiores detalhes da proposta, ver www.nossareformatributaria.com.br. Esse percentual foi comunicado pelo relator da reforma tributária, Deputado Sandro Mabel, quando da apresentação de seu substitutivo em Seminário realizado no Centro de Extensão Universitária, em São Paulo, em 13 de março de 2009.

$21 \quad$ Para 2007, isso significaria que a Seguridade Social perderia $\mathrm{R} \$ 43,6$ bilhões (os recursos da DRU já estariam deduzidos) (CARVALHO, 2010).
} 
ciamento foi destaque na agenda de problemas no âmbito da saúde universal, ao longo dos anos 1990 e 2000.

Observa-se que, ao mesmo tempo que se implanta o SUS, com base nos princípios de um sistema público e universal, não se percebe melhoria na situação econômica, agravando a crise fiscal e financeira do Estado e levando a que os governos federais, em destaque os do período Lula, limitassem o aporte de recursos para a Seguridade Social e para a saúde.

As possibilidades de valorização dos direitos universais à saúde, por meio da prioridade ao financiamento do SUS, podem ser alcançadas por outros percursos. É claro que a opção do projeto do governo federal deveria ser em outra direção: elevar a saúde universal à condição prioritária de suas políticas. Isso porque os novos compromissos deveriam estar condicionados à busca de uma proteção à atual crise mundial e de construção de um projeto de desenvolvimento econômico e social, o que implicaria a ruptura da lógica da política econômica perseguida pelos governos Lula, em aliança aos interesses do capital portador de juros. Uma possibilidade concreta desse projeto seria buscar a construção de consenso político institucional em prol das políticas universalistas, assegurando o modelo de desenvolvimento econômico com ampliação dos direitos sociais. Para tanto, a partir da valorização de um "princípio de construção da universalidade" são sugeridas as seguintes propostas: $:^{22}$

a) ampliar a defesa pela construção de uma política macroeconômica que supere o quadro da política mantida pelos governos Lula, ancorada no regime de metas para a inflação, enfrentando os interesses daqueles que se beneficiam dos juros elevados e da insensatez da valorização de nossa moeda. Para isso, será necessário que as decisões das políticas econômicas procurem sempre privilegiar os objetivos sociais, no sentido de garantir uma proteção social (direitos sociais) de forma mais segura e definitiva, por meio do provimento de maior sustentabilidade financeira para a seguridade social e para o SUS;

b) perseguir a meta de aplicar, no mínimo, $6 \%$ do PIB em saúde pública, garantindo a universalidade da saúde (SUS);

c) assegurar a universalidade, principalmente no cenário da crise mundial no capitalismo contemporâneo sob o domínio do capital portador de juros, a fim de garantir mais recursos, por meio de propostas alternativas de financiamento, sem abrir mão da manutenção do financiamento da seguridade social. Assim, poderiam ser discutidas e apresentadas as seguintes propostas:

22 Algumas dessas propostas foram apresentadas pelo Fórum em Defesa do SUS e contra a privatização e aprovadas na $14^{\mathrm{a}}$ Conferência Nacional de Saúde, realizada no final de novembro 2011, ver material/documentos da Frente Nacional contra a Privatização do SUS. Disponível em: < http:// forumsus.blogspot.com>. Acesso em: 12 dez. 2011. 
-a ampliação da alíquota da CSLL para instituições financeiras (atual 9\%);

-o aprofundamento dos mecanismos de tributação para a esfera financeira, mediante a criação de um Imposto Geral sobre a Movimentação Financeira (IGMF) e a tributação das remessas de lucros e dividendos realizadas pelas empresas multinacionais, atualmente isentas na legislação;

-o estabelecimento da Contribuição sobre Grandes Fortunas com destinação para a Seguridade Social (projetos já existentes na Câmara federal);

d) buscar o entendimento sobre o fim das isenções de Imposto de Renda das Pessoas Físicas com despesas médicas e do Imposto de Renda das Pessoas jurídicas das empresas que prestam assistência médica a seus funcionários;

e) estabelecer uma política de renúncia fiscal para Entidades sem fins lucrativos e para a indústria farmacêutica, sem prejuízo da capacidade do gasto do Estado, especialmente nas políticas de direitos sociais, como a saúde;

f) resistir à aprovação da reforma Tributária do Governo Lula, não permitindo o desmonte da pluralidade e a exclusividade das fontes de financiamento da Seguridade Social;

g) rejeitar a permanência da DRU, como forma de não prejudicar a "saúde" financeira do Orçamento da Seguridade Social.

Essas medidas, somadas à garantia de um mínimo de compromisso do governo federal (que a proposta de regulamentação da EC 29 pressupunha ser de 10\% de seus recursos), podem abrir caminho para o país, de fato, implantar o direito universal da saúde, aproximando sua despesa, enquanto proporção do Produto Interno Bruto, dos demais países que contam com um sistema público universal de saúde.

\section{Referências}

ASSOCIAÇÃO NACIONAL DOS AUDITORES FISCAIS DA RECEITA FEDERAL DO BRASIL (ANFIP). Análise da Seguridade Social em 2010. 2011. Disponível em: <www.anfip.org.br>. Acesso em: 10 ago. 2011.

BEHRING, E. R. Acumulação capitalista, fundo público e política social. In: BOSCHETTI, I. et al.(Org.). Política Social no Capitalismo: Tendências Contemporâneas. São Paulo: Cortez, 2008.

BRASIL. Ministério da Fazenda. Carta de intenção referente ao novo acordo. 2004. Disponível em: <http://www.fazenda.gov.br>. Acesso em: 10 dez. 2004. 
CARVALHO, G. Tensões e Contradições da Conjuntura Atual do Financiamento do SUS. In: SEMINÁRIO PERSPECTIVAS DO FINANCIAMENTO PARA O ACESSO UNIVERSAL DA SAÚDE NO BRASIL, 2010, São Paulo. Anais... São Paulo: Faculdade de Saúde Pública da USP, 2010.

CHESNAIS, F. O Capital Portador de Juros: Acumulação, Internacionalização, Efeitos Econômicos e Políticos. In: CHESNAIS, F. (Org.). A Finança Mundializada, Raízes Sociais e Políticas, Configuração, Consequências. São Paulo: Boitempo, 2005.

. Les Dettes Illégitimes: Quand Lês Banques Font Main Basse Sur Les Politiques Publiques. Paris : Raison d'Agir, 2011.

HUSSON, M. Les Casseurs de l'État Social: Des Retraites a La Sécu, La Grande Démolition. Paris: Découverte, 2003.

MAAR, W. L. O Eclipse da Política na Experiência Social Brasileira. Margem Esquerda: Ensaios Marxistas, São Paulo, n. 9, 2007.

MARQUES, R. O Regime de Acumulação sob a dominância financeira e a Nova Ordem no Brasil. In: MARQUES, R.; FERREIRA, M. (Org.). O Brasil sob a Nova Ordem: A Economia Brasileira Contemporânea: Uma Análise dos Governos Collor a Lula. São Paulo: Saraiva, 2009.

MARQUES, R.; MENDES, A. L'action du gouvernement Lula dans le domaine social: une lecture complexe. In: CENTRE TRICONTINENTAL ET ÉDITIONS SYLLEPSE (Org.). Le Brésil de Lula: un bilan contrasté. Paris: Éditions Syllepse, 2010. Vol. 17, p. 87-103.

. Crônica de uma Crise Anunciada: O Financiamento do SUS sob a Dominância do Capital Financeiro. In: ENCONTRO NACIONAL DE ECONOMIA POLÍTICA, 14., São Paulo, 2009. Anais... São Paulo: PUC-SP, 2009.

MARQUES, R.; MENDES, A.; UGINO, C. K. A Previdência Social em Pauta: Notas para Reflexão. Argumentum, Vitória, v. 2, n. 1, p. 5-19, jan./jun. 2010.

MARQUES, R.; NAKATANI, P. A Crise Mundial e a Economia Brasileira. Texto preparado para a reunião da Red de Estudios de la Economía Mundial (REDEM), Santiago do Chile, em 13 e 14 de outubro de 2011.

MARX, K. El Capital: Crítica de la Economía Política. México: Fondo de Cultura Econômica, 1987. v. 3.

MENDES, A. Financiamento, Gasto e Gestão do Sistema Único de Saúde (SUS): A Gestão Descentralizada Semiplena e Plena do Sistema Municipal no Estado de São Paulo (1995-2001). 2005. 422 f. Tese (Doutorado em Economia) - Instituto de Economia, Universidade Estadual de Campinas, Campinas, 2005.

MESA-LAGO, C. Desarrollo Social, Reforma del Estado y de La Seguridad Social, Al Umbral Del Siglo XXI. Santiago do Chile: ONU: Cepal, 2000.

PARIS, V; M.; DEVAUX; WEI, L. Health Systems Institutional Characteristics: A Survey of 29 OECD Countries. 2010. Disponível em: <http://www.oecd-ilibrary.org/social-issuesmigration-health/oecd-health-working-papers_18152015>. Acesso em: 10 abr. 2011.

PAULANI, L. O Brasil na crise da acumulação financeirizada. In: ENCUENTRO INTERNACIONAL DE ECONOMÍA POLÍTICA Y DERECHOS HUMANOS, 4., Buenos Aires, 2010. Anais... Buenos Aires: Madres, 2010. 
PIOLA, S. Financiamento da Seguridade Social e do SUS: desafios e perspectivas. In: SEMINÁRIO PERSPECTIVAS DO FINANCIAMENTO PARA O ACESSO UNIVERSAL DA SAÚDE NO BRASIL, 2010, São Paulo. Anais... São Paulo: Faculdade de Saúde Pública da USP, 2010.

SERVO, L. M. S. et al. Financiamento e Gasto Público de Saúde: Histórico e Tendências. In: MELAMED, C.; PIOLA, S. F. (Org.). Políticas Públicas e Financiamento Federal do Sistema Único de Saúde. Brasília: IPEA, 2011.

SOARES, S et al. Os Impactos do Benefício do Programa Bolsa Família sobre a Desigualdade e a Pobreza. In: CASTRO, J. A.; MODESTO, L. Bolsa Família 2003 - 2010: Avanços e Desafios. Brasília: IPEA, 2010. v. 2.

THOMSON, S.; FOUBISTER, T.; MOSSIALOS, E. Financing Health Care in the European Union: Challenges and Policy Responses. Observatory Studies Series, n. 17, 2009. Disponível em: < http://www.euro.who.int/en/home/projects/observatory/publications/studies $>$. Acesso em: 10 abr. 2011.

WORLD HEALTH ORGANIZATION (WHO). World Health Statistics 2008. Genève: WHO Press, 2008.

Recebido em: 16/01/2012.

Aceito em: 24/04/2012. 